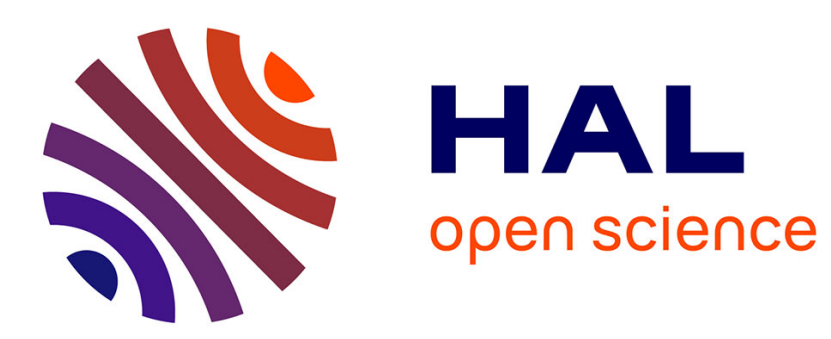

\title{
A numerical study of the penetration test at constant rod velocity
}

Quoc Anh Tran, Bastien Chevalier, Pierre Breul

\section{To cite this version:}

Quoc Anh Tran, Bastien Chevalier, Pierre Breul. A numerical study of the penetration test at constant rod velocity. 14th IACMAG International Conference, Sep 2014, Kyoto, Japan. hal-01126776

\section{HAL Id: hal-01126776 \\ https://hal.uca.fr/hal-01126776}

Submitted on 6 Mar 2015

HAL is a multi-disciplinary open access archive for the deposit and dissemination of scientific research documents, whether they are published or not. The documents may come from teaching and research institutions in France or abroad, or from public or private research centers.
L'archive ouverte pluridisciplinaire HAL, est destinée au dépôt et à la diffusion de documents scientifiques de niveau recherche, publiés ou non, émanant des établissements d'enseignement et de recherche français ou étrangers, des laboratoires publics ou privés. 


\title{
A numerical study of the penetration test at constant rod velocity
}

\author{
Q.A. Tran, B. Chevalier \& P. Breul \\ Institut Pascal UMR CNRS, Université Blaise Pascal, Clermont-Ferrand, France
}

\begin{abstract}
Penetration tests are widely used in geotechnical engineering for the on site characterization of mechanical properties of soils. This paper proposes a numerical study of static penetration tests on granular material using Discrete Element Method and in particular molecular dynamics in 2 dimensions (Cundall and Strack, 1979). The results first showed the ability of the model to reproduce qualitatively the results of penetration tests classically obtained in experimental conditions. Then, the energy balance of the test is analyzed at the macroscopic and microscopic to understand local parameters influencing this test and how to interpret this test. The most part of the source energy is irreversibly lost and dissipated by friction in the contacts between particles; the remaining part of energy is stored by the upper confining wall. The sample area mobilized by frictional dissipation remains approximately the same as penetration velocity increases but the dissipated energy level increases for particles in this area.
\end{abstract}

\section{INTRODUCTION}

In the field of in situ mechanical characterization of mechanical properties of soils, penetration tests are commonly used. Penetration tests can measure the properties of soils in the domain of large deformations. The tip resistances, deduced from pile driving theory, can be measured either in dynamic conditions $\left(q_{d}\right)$ either in constant velocity conditions $\left(q_{c}\right)$. However, Chaigneau (2001) and Benz-Navarrete (2009) showed that tip resistance depends on the solicitation mode used in the penetration process. Thus, in order to properly control the result and to better interpret the in-situ test, the process of penetration must be analyzed at the microscopic scale.

Discrete Element Method (DEM) is an effective tool to analyze at different scales the behavior of granular materials and in particular soils ( $\mathrm{Yu}$ et al. 2013). DEM is particularly useful in the case of penetration tests, where large deformations are observed and where the solicitation is highly non homogeneous. In this paper, a numerical model of penetration tests using DEM is proposed for the reproduction of tests in constant velocity conditions. The software $\mathrm{PFC}^{2 D}$ (Itasca) was used, based on Molecular Dynamics (MD) (Cundall et al. 1979).

Many authors proposed numerical models for reproducing penetration tests in static conditions or in constant velocity conditions in 2D (Huang and Ma, 1994, Calvetti and Nova 2005, Jiang et al. 2006) and in 3D (Benz-Navarrete 2009, Arroyo et al. 2011, McDowell et al. 2012, Quezada et al. 2013).

In this paper, we aim to develop a numerical model to reproduce a penetrometer test (Fig. 1). Then, the model is used to analyze of the mechanisms of the transmission and of the dissipation of energy

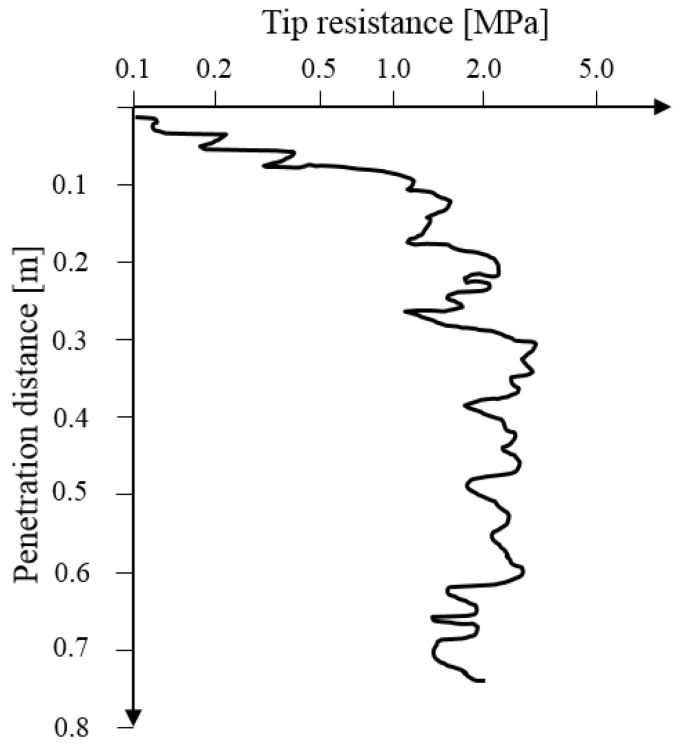

Figure 1. Example of penetration test (Benz-Navarrete (2009)).

during the penetration procedure. Effect of penetration velocity has also been investigated to evaluate its influence on the micro-macroscopic results.

\section{NUMERICAL PENETRATION TEST IN CONSTANT VELOCITY CONDITON}

\section{$2.1 \quad$ Numerical model}

DEM based on MD in 2-dimensions was used (Cundall and Strack. 1979). Granular material samples of 
10000 cylindrical particles of length $4 \mathrm{~mm}$ were tested. The samples were generated in a rectangular box of $0.60 \mathrm{~m}$ in width and of $0.45 \mathrm{~m}$ in height. A ratio of 2 was chosen between the diameters of largest and smallest particle. Linear contact law was chosen with normal and tangential contact stiffness respectively equal to $k_{n}=5 \times 10^{5} \mathrm{~N} \cdot \mathrm{m}^{-1}$ and $k_{s}=3.75 \times 10^{5} \mathrm{~N} \cdot \mathrm{m}^{-1}$. A Coulomb friction criterion of coefficient $\mu=1.00$ was used to limit the value of tangential force relatively to normal force. The normal stiffness ratio between the particles and the walls equals 100 . The time step is equal to $10 \%$ of the critical time. No viscous damping was considered in the contact model. No local damping (Cundall et al. 1982) was used in the model.

The sample preparation broke down into 3 steps. First, frictionless particle radius expansion method without gravity was used in order to reach a sample porosity of $\eta=0.15$. Second, the final value of friction coefficient was applied as well as gravity. The sample was then stabilized until equilibrium state was reached and top wall was removed. At the end of this step, the samples presented an 'at rest' earth pressure ratio $K_{0}$ equal to 0.5 . Finally, a vertical confining pressure was applied on the top of samples. The confining pressure was used to simulate an overlaying layer of material that prevented the effect of free surface to be observed (Chaigneau 2001); usually in homogeneous soils, tip resistance increases with depth until a critical depth is reached over which tip resistance becomes steady. The vertical confining pressure on top wall is equivalent to an overlaying layer of thickness equal to $1.80 \mathrm{~m}$. Finally, the order of magnitude of the level of stiffness of particles (Combe. 2002) was of 1000.

The penetration tests were conducted on three different samples $S_{1}, S_{2}$ and $S_{3}$ generated with the same process. The penetration was conducted with a frictionless rod of width $14 \mathrm{~mm}$ linked to a pike of $16 \mathrm{~mm}$ width at its bottom edge and presenting a friction coefficient of 0.3 .

The diameter ratio between the tip and the average particle is equal to 3.03 . The ratio between the wide of the mold and the tip diameter is equal to 37.5 . The mass of rod and tip is $0.5 \mathrm{~kg}$.

\subsection{Model validation}

In constant velocity conditions, the rod is driven in the sample with a velocity of $2.5 \mathrm{~cm} \cdot \mathrm{s}^{-1}$. Figure 2 shows the tip resistance $F_{c}$ versus the depth in the sample.

Density of probability of tip force $F_{c}$ at different depths is shown in Figure 3. Thus, the peak force $F_{c}$ is stable as a function of depth and we do not observe an effect of critical depth at the beginning of penetration test.

Furthermore, the probability density values of $F_{c}$ obtained between $5 \mathrm{~cm}$ and $30 \mathrm{~cm}$ for three samples is shown in Figure 4. A very good repeatability of the penetration test was obtained in static conditions. The average values of $F_{c}$ obtained for the three samples are very similar.

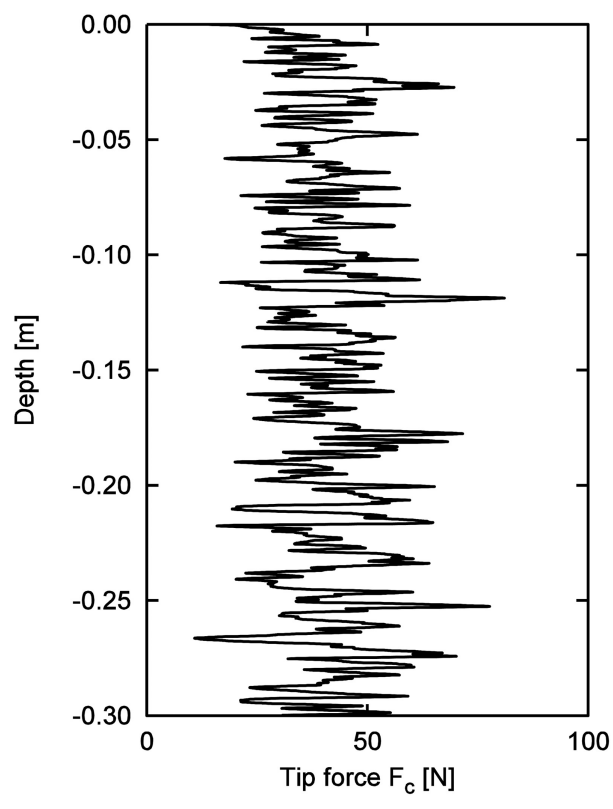

Figure 2. Tip force $F_{c}$ versus penetration distance.

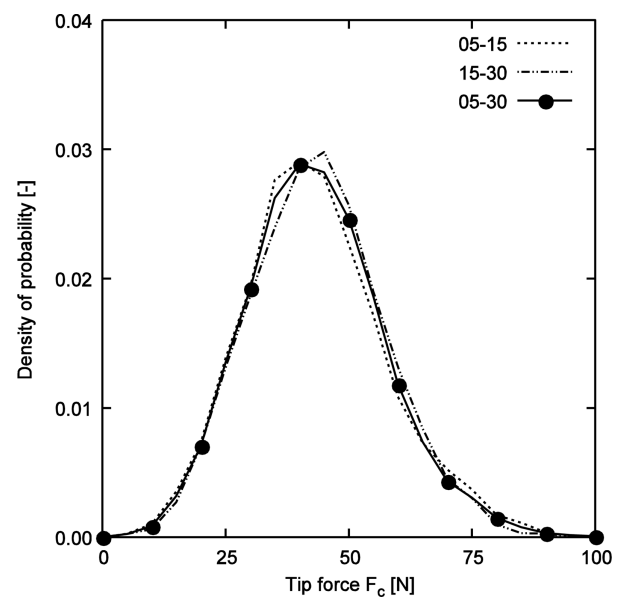

Figure 3. Density of probability of tip force $F_{c}$ for different depth ranges: from 5 to 15,15 to 30 and 5 to $30 \mathrm{~cm}$.

The coordination number in a rectangular area $5 \mathrm{~cm} \times 5 \mathrm{~cm}$ around the tip is measured during the penetration test. Note that the value is stable in function of depth (Fig. 5). The average coordination number in this zone is equal 2.64.

\section{ENERGY BALANCE}

The way the energy is dissipated or stored is investigated here. The system considered here is composed of the granular material and the upper confining wall, which represents an overlaying layer of granular material. In this system, the sources of energy are 


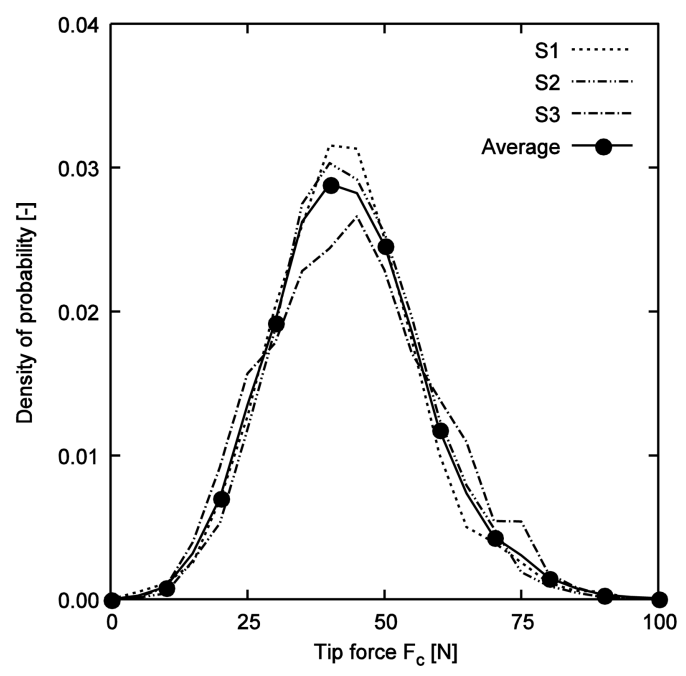

Figure 4. Density of probability of tip force $F_{c}$ for constant velocity tests for samples $S_{1}, S_{2}$ and $S_{3}$.

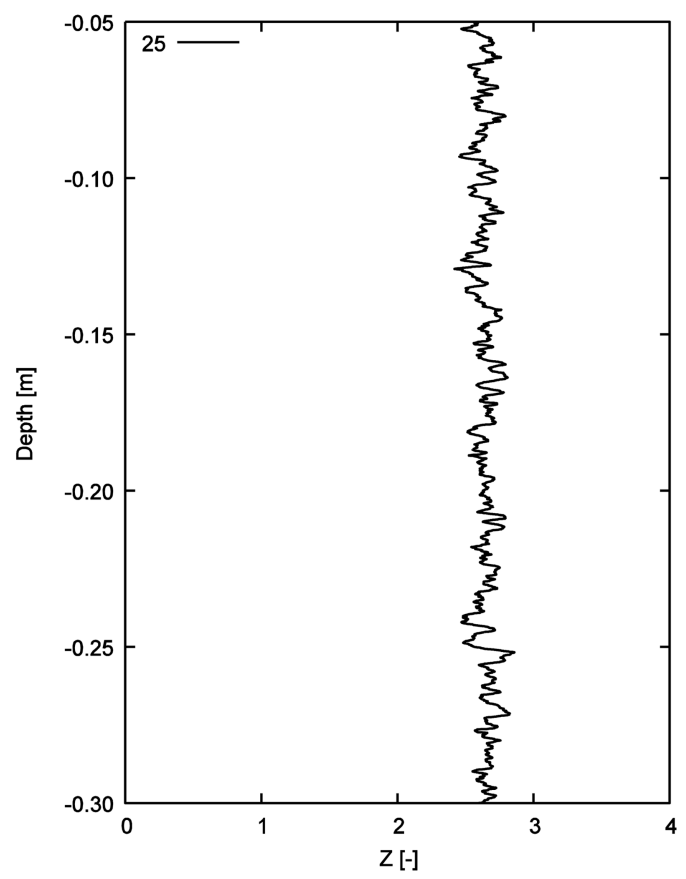

Figure 5. Coordination number versus penetration distance.

represented by the work of the tip force $E_{F c}$. There are 4 modes of storage of the energy in the system: the kinetic energy of grains $E_{K}$, the strain energy $E_{S}$, the potential energy of grains $E_{P}$ and the energy absorbed or restituted by the upper confining stress $E_{C}$. The only dissipation mode is represented by friction $E_{F}$. The energy balance can be written as follows:

$$
E_{F c}=E_{F}+E_{C}+E_{P}+E_{K}+E_{S}
$$

Table 1. Energy balance of the static penetration test with rod velocity equal to $2.5 \mathrm{~cm} \cdot \mathrm{s}^{-1}$.

\begin{tabular}{lllllllll}
\hline & & \multicolumn{7}{c}{ Dissipation or Transmission } \\
\cline { 3 - 8 } $\mathrm{V}$ & Injection \\
\cline { 4 - 8 }$/ \mathrm{s}]$ & Energy & $E_{\text {Signal }}$ & $E_{F}$ & $E_{C}$ & $E_{P}$ & $E_{K}$ & $E_{S}$ \\
\hline 25 & {$[\mathrm{~J}]$} & 12.01 & 10.64 & 1.21 & 0.12 & 0.00 & 0.11 \\
& {$[\%]$} & 100 & 87.81 & 10.08 & 0.96 & 0.02 & 1.13 \\
\hline
\end{tabular}

The energy $E_{C}$ is equal to the work of the equivalent confining force on upper wall during the penetration test. The energy $E_{F}$ is equal to the total work of the tangential component of forces in the contacts existing or that existed in the system between the considered initial and the final states. $E_{F}$ has to be calculated for each time step through all the existing contacts. For one single time step $\Delta t$, the increment $\Delta E_{F}$ is equal to:

$$
\Delta E_{F}=\sum_{1}^{N c} F_{T}(\mathrm{t}) \mathrm{V}_{T}(\mathrm{t}) \mathrm{dt}
$$

with $N_{C}$ the number of contact in the system, $F_{T}(t)$ the tangential force of the contact, and $V_{T}(t)$ the tangential velocity of the contact point.

The result of the energy balance is given in Table 1 . A difference of less than $0.56 \%$ was observed between the total of energy sources and the total of energy dissipated or stored in the system, probably due to the difference in the initial and final equilibrium state. The most part $(\sim 88 \%)$ of the source energy is irreversibly lost and dissipated by friction in the contacts between particles; the remaining part of energy $(\sim 10 \%)$ is stored by the upper confining wall.

In order to understand the mechanisms involved in the static penetration test and especially concerning the energy dissipation, the study of energy distributions is proposed for the static test presented. The energy dissipated in each contact was equally shared by each particle involved in the contact. The distribution of the energy dissipated by friction by each particle is shown on Figure 6 for the static penetration test with rod velocity equal to $2.5 \mathrm{~cm} \cdot \mathrm{s}^{-1}$. Obviously, it can be observed that the dissipation by friction takes place in the vicinity of the pike. The boundary conditions selected therefore have little influence on the observed phenomena.

\section{PENETRATION VELOCITY}

In this section, we study the effect of rod velocity on the penetration process with constant rod velocity by varying the rod velocity of $2.5 \mathrm{~cm} \cdot \mathrm{s}^{-1}$ to $5 \mathrm{~m} \cdot \mathrm{s}^{-1}$ for the three samples $\mathrm{S}_{1}, \mathrm{~S}_{2}, \mathrm{~S}_{3}$.

Figure 7 shows the average tip force between 5 and $30 \mathrm{~cm}$ as a function of rod velocity. It was found that more rod velocity increases, tip force $F_{c}$ increases. In addition, the standard deviation increases when sink rate increases (Fig. 8). Despite no viscosity was considered in the contact model, a time-dependent 


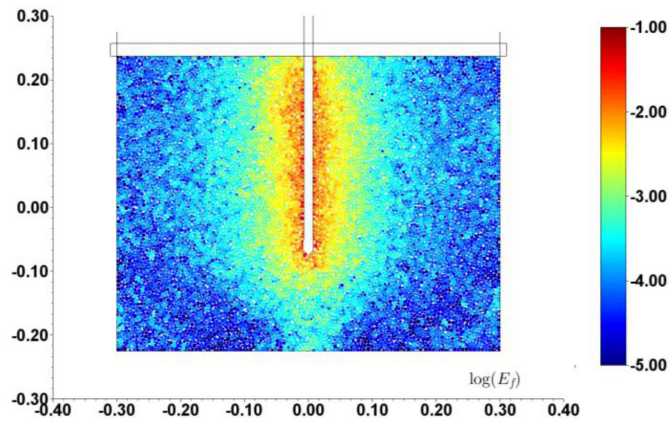

Figure 6. Accumulated energy dissipated by friction for each particle during the static test up to $30 \mathrm{~cm}$ deep with rod velocity equal to $2.5 \mathrm{~cm} \cdot \mathrm{s}^{-1}$.

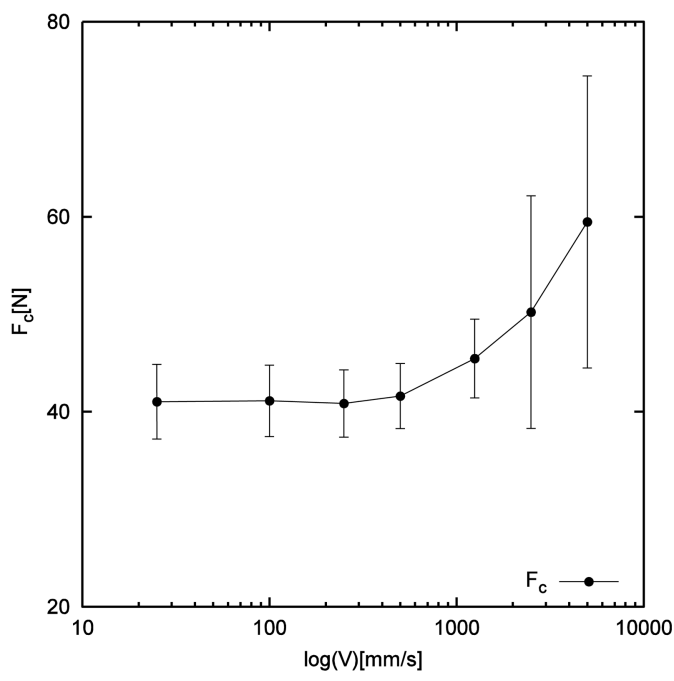

Figure 7. Tip force $F_{c}$ as a function of rod velocity.

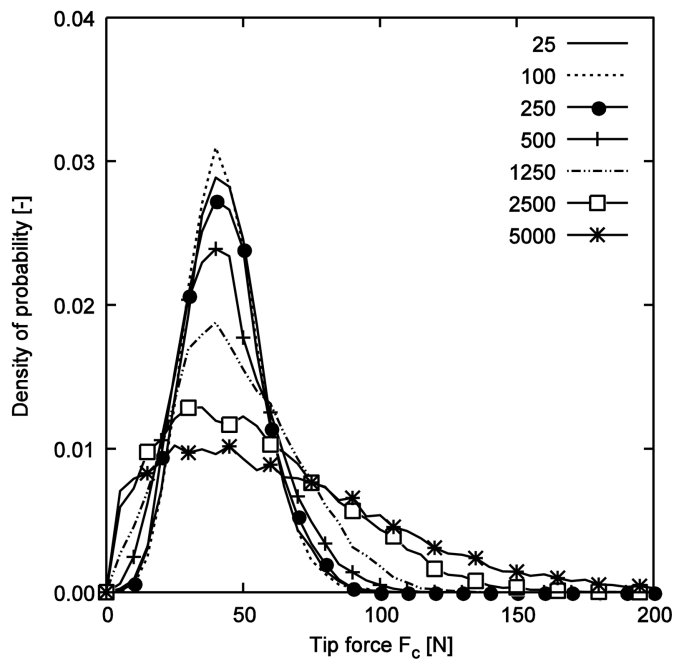

Figure 8. Density of probability of tip force $F_{c}$ for different rod velocities from 25 to $5000 \mathrm{~mm} \cdot \mathrm{s}^{-1}$.
Table 2. Energy balance of the static penetration test at different rod velocities.

\begin{tabular}{llllllll}
\hline & & \multicolumn{7}{c}{ Dissipation or Transmission } \\
\cline { 3 - 8 } $\mathrm{V}$ & Injection & & \\
{$[\mathrm{mm} / \mathrm{s}]$} & Energy & $E_{\text {Signal }}$ & $E_{F}$ & $E_{C}$ & $E_{P}$ & $E_{K}$ & $E_{S}$ \\
\hline 25 & {$[\%]$} & 100 & 88.07 & 10.05 & 0.95 & 0.00 & 0.92 \\
100 & {$[\%]$} & 100 & 87.81 & 10.08 & 0.96 & 0.02 & 1.13 \\
1250 & {$[\%]$} & 100 & 88.36 & 8.51 & 0.80 & 0.33 & 2.01 \\
2500 & {$[\%]$} & 100 & 90.33 & 7.64 & 0.74 & 0.36 & 0.93 \\
5000 & {$[\%]$} & 100 & 90.71 & 6.99 & 0.70 & 0.94 & 0.50 \\
\hline
\end{tabular}

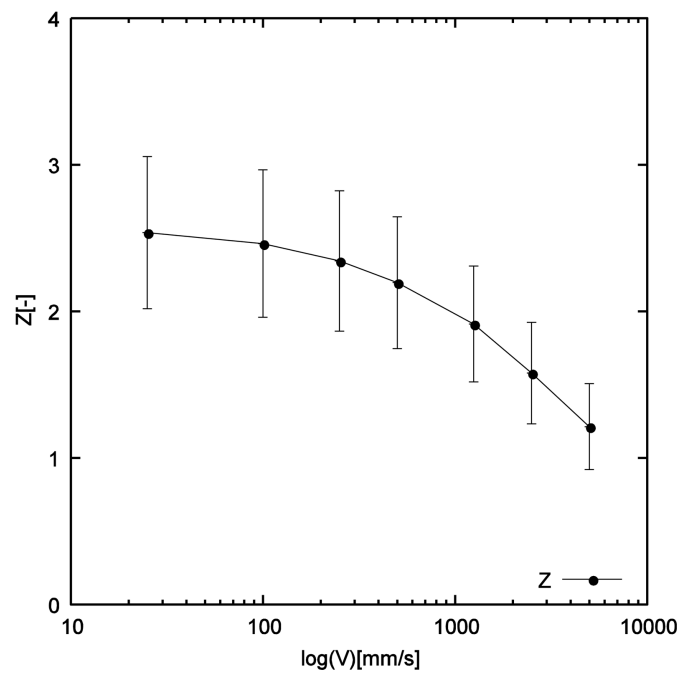

Figure 9. Mean coordination number as a function of rod velocity.

behavior was observed due to the grains rearrangement variations for the different driving velocities.

Figure 9 shows the average number of coordination for the previous penetration tests by varying the rod velocity. It is seen that the number of coordination decreases when the driving speed increases.

In terms of energy, an analysis of the energy balance is analyzed. Table 2 shows the different energy components for penetration tests at different speeds driving. It is observed that the proportion of energy dissipated by friction increases with rod velocity to the detriment of the energy corresponding to the work of confinement $E_{C}$.

In section 3, it was shown that the distribution where the energy is dissipated by friction the more important is around the tip. Moreover, when the driving speed increases in the same overall volume of the system, the work of friction between the particles and the tip increases (Fig. 10). Thus, the frictional dissipation is more effective.

Figures 11 and 12 shows the distributions of energy dissipated by friction on reduced interval $(1 \mathrm{~cm})$ during the static penetration test at different rod velocities 


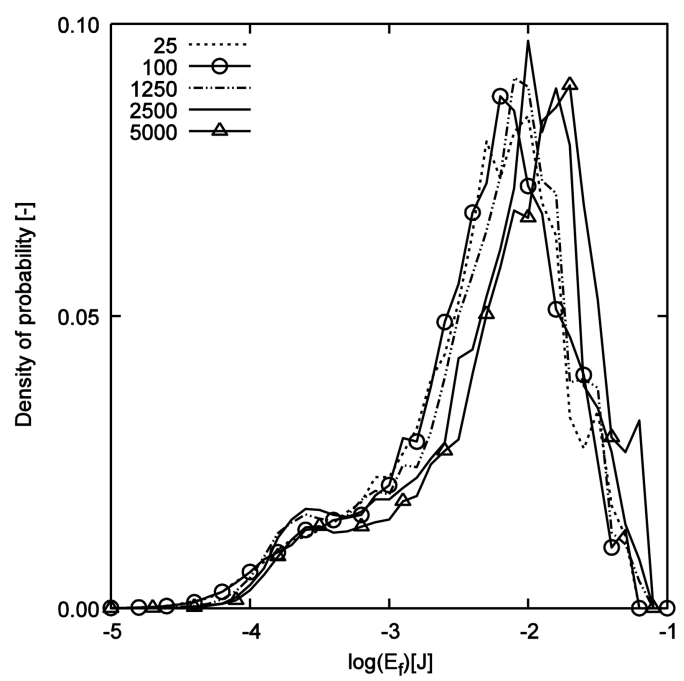

Figure 10. Density of probability of the energy dissipated by friction between the particles $\left(\mathrm{mm} \cdot \mathrm{s}^{-1}\right)$.

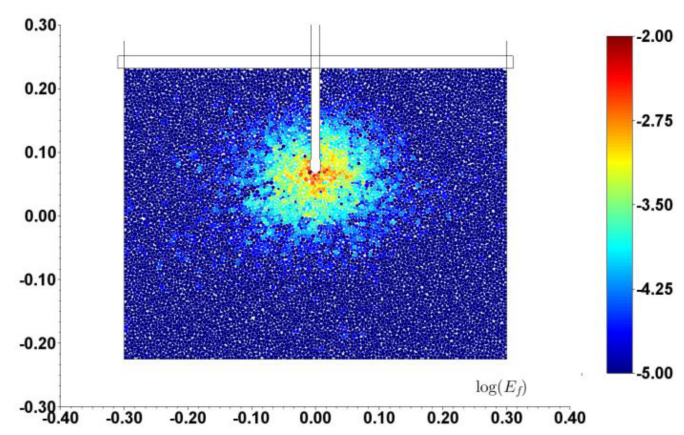

Figure 11. Distribution of energy dissipated by friction on reduced interval $(1 \mathrm{~cm})$ during the static penetration test with rod velocity equal to $10 \mathrm{~cm} \cdot \mathrm{s}^{-1}$.

$\left(10 \mathrm{~cm} \cdot{ }^{-1}\right.$ and $\left.250 \mathrm{~cm} \cdot \mathrm{s}^{-1}\right)$. It is found that the dissipated energy zone by friction is more effective when the rod velocity increases.

Furthermore, it is noted that the potential energy of grains $\left(E_{P}\right)$ and strain energy $\left(E_{S}\right)$ are little affected by the increase of rod velocity.

\section{CONCLUSION}

In this paper, a 2-D discrete numerical model was proposed to model penetration tests in granular materials. No damping (or viscous or local) was used in this model so as not to artificially affect the mechanisms of energy dissipation in the granular material during the penetration test. A good repeatability of the tests was observed. The effect of free surface could be cancelled by the upper confining pressure.

The analysis of the energy balance in the granular material during the dynamic test reveals that most of the energy injected into the system is dissipated by

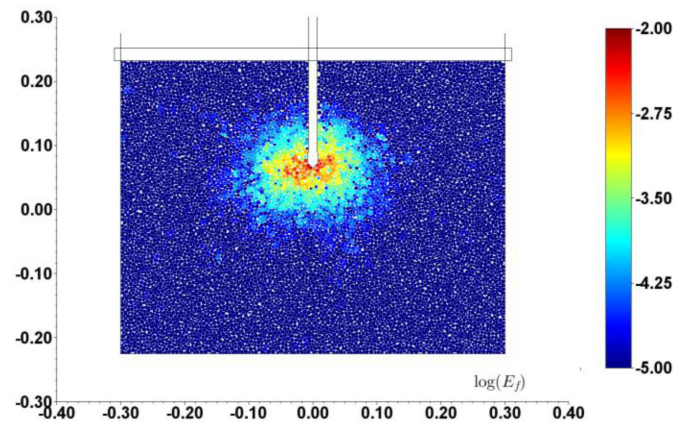

Figure 12. Distribution of energy dissipated by friction on reduced interval $(1 \mathrm{~cm})$ during the static penetration test with rod velocity equal to $250 \mathrm{~cm} \cdot \mathrm{s}^{-1}$.

friction. Despite the deliberate absence of any damping in the model, the energy balance reveals that the upper confining pressure plays the role of damping, with a ratio of $10 \%$ of the total energy.

The variation of the driving speed in the penetration test leads to different responses of the sample, even without viscosity in the contact model. The frictional dissipation becomes more effective when the driving speed increases. Consequently, the effect of boundary conditions and therefore the dissipation due to the upper confining wall decreases when the driving speed increases. In addition, the coordination number decreases when the speed increases during the driving test of penetration at a constant speed.

\section{REFERENCES}

Arroyo, M., Butlanska, J., Gens, A., Calvetti, F. \& Jamiolkowski, M. 2011. Cone penetration tests in a virtual calibration chamber. Géotechnique 61(6): 525-531.

Benz Navarrete, M. 2009. Mesures dynamiques lors du battage du pénétromètre Panda 2. Clermont-Ferrand: Université Blaise Pascal

Calvetti, F. \& Nova, R. 2005. Micro-macro relationships from DEM simulated element and in-situ tests. Proc. 5th Int. Conf. Micromech. Granular Media: Powders and Grains 2005, Stuttgart: 245-250.

Chaigneau, L. 2001. Caractérisation des milieux granulaires de surface à l'aide d'un pénétromètre. Clermont-Ferrand: Université Blaise Pascal.

Combe G. 2002. Mécanique des matériaux granulaires et origines microscopiques de la déformation. Etudes et Recherches $d u$ Laboratoire Central des Ponts et Chaussées, SI8.

Cundall P. A. \& Strack O. D. L. 1979. A discrete numerical model for granular assemblies. Géotechnique 29(1): 4765.

Cundall P.A., Drescher A. \& Strack O.D.L. 1982. Numerical experiments on granular assemblies: measurements and observations. IUTAM Conf. on Deformation and Failure of Granular Materials, Delft: 355-370.

Huang, A.B. \& Hsu, H.H. 2004. Advanced calibration chambers for cone penetration testing in cohesionless soils. ISC2 Geotech. and Geophys. Site Characterization, Porto: 147-166. 
Huang, A.B. \& Ma, M.Y. 1994. An analytical study of cone penetration test in granular material. Canadian Geotechnical Journal 3(1): 91-103.

Jiang, M.J., Yu, H.-S. \& Harris, D. 2006. Discrete element modeling of deep penetration in granular soils. International Journal for Numerical and Analytical Methods in Geomechanics 30(4): 335-361.

McDowell, G.R., Falagush, O. \& Yu, H.S. 2012. A particle refinement method for simulating DEM of cone penetration testing in granular materials. Géotechnique Letters 2: 141-147.
Quezada, J.C., Saussine, G., Breul, P. \& Radjai, F. 2013. Penetration strength of coarse granular materials from DEM simulations. Proc. of the 7th Int. Conf. on Micromechanics of Granular Media: Powders and Grains 2013, Sydney: 241-244.

Yu, A., Dong, K., Yang, R. \& Luding, S. (Eds). 2013. Proc. of the 7th Int. Conf. on Micromechanics of Granular Media: Powders and Grains 2013, Sydney. 